\section{BRAZIULIAN JOURNAL}

OF MEDICAL AND BIOLOGICAL RESHARCH

www.bjournal.com.br
ISSN 0100-879X

Volume 43 (10) 914-1009 October 2010

BIOMEDICAL SCIENCES

AND

CLINICAL INVESTIGATION

Braz J Med Biol Res, October 2010, Volume 43(10) 950-956

doi: 10.1590/S0100-879X2010007500082

Caspase dependence of the death of neonatal retinal ganglion cells induced by axon damage and induction of autophagy as a survival mechanism

C. Sternberg, M. Benchimol and R. Linden

The Brazilian Journal of Medical and Biological Research is partially financed by
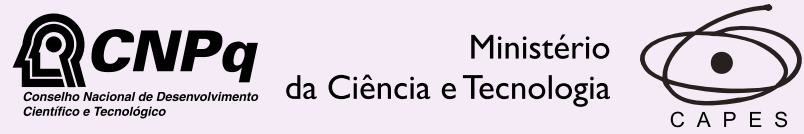

Ministério da Educação

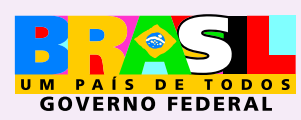

DTAPESP

Institutional Sponsors
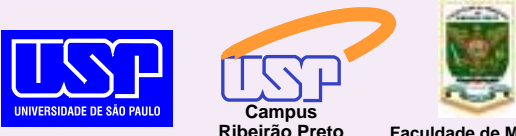

Ф SHIMADZU

GE Healthcare
Hotsite of proteomics metabolomics developped by:

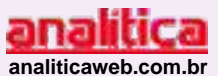

Thermo
SCIEN TIFIC 


\title{
Caspase dependence of the death of neonatal retinal ganglion cells induced by axon damage and induction of autophagy as a survival mechanism
}

\author{
C. Sternberg ${ }^{1}$, M. Benchimol ${ }^{2}$ and R. Linden ${ }^{1}$ \\ ${ }^{1}$ Instituto de Biofísica, Universidade Federal do Rio de Janeiro, Rio de Janeiro, RJ, Brasil \\ 2Universidade Santa Úrsula, Rio de Janeiro, RJ, Brasil
}

\begin{abstract}
We examined the degeneration of post-mitotic ganglion cells in ex-vivo neonatal retinal explants following axon damage. Ultrastructural features of both apoptosis and autophagy were detected. Degenerating cells reacted with antibodies specific for activated caspase- 3 or -9 , consistent with the presence of caspase activity. Furthermore, peptidic inhibitors of caspase-9, -6 or -3 prevented cell death (100 $\mu \mathrm{M}$ Ac-LEDH-CHO, $50 \mu \mathrm{M}$ Ac-VEID-CHO and $10 \mu \mathrm{M}$ Z-DEVD-fmk, respectively). Interestingly, inhibition of autophagy by $7-10 \mathrm{mM} 3$-methyl-adenine increased the rate of cell death. Immunohistochemistry data, caspase activation and caspase inhibition data suggest that axotomy of neonatal retinal ganglion cells triggers the intrinsic apoptotic pathway, which, in turn, is counteracted by a pro-survival autophagic response, demonstrated by electron microscopy profiles and pharmacological autophagy inhibitor.
\end{abstract}

Key words: Apoptosis; Autophagy; Caspases; Retina; Central nervous system

\section{Introduction}

The mechanism by which central neurons undergo cell death after axonal injury is not clear (1-4). Several studies indicate that it may be due to blockade of retrograde axonal transport of neurotrophins $(5,6)$, the triggering of damage signals (7), or other still unidentified mechanisms.

In adult rats, retinal ganglion cells (RGCs) undergo apoptosis throughout the course of several diseases, such as ocular hypertension, axotomy, ischemic insults, and stress-mediated degeneration of photoreceptors (4,8-13). In neonatal rats, axotomy also induces cell degeneration $(4,14,15)$ and is prevented by inhibition of protein synthesis $(4,16)$, growth factors $(14,17)$, inhibition of caspases $(4)$, reduced redox state (18), or overexpression of Bcl-2 (19).

A thorough study has shown the involvement of the apoptotic proteases, caspase-9 and -3, in axotomy-induced RGC death in retinal explants from postnatal day 6 (PD6) mice (20). Furthermore, ablation of the superior colliculus of PD2 rats induces a massive and rapid increase in RGC death that is not accompanied by activation of caspase- 3
(21). Therefore, the involvement of caspases in axotomyinduced death of retinal ganglion cells in the neonatal retina needs to be established.

Programmed cell death can take several forms, such as autophagic cell death (for a review, see Ref. 22,23), and apoptosis is not the only program of execution of cell death that may be involved in the demise of the retina. Light stress induces ultrastructural changes in rat rod photoreceptors, and an early sign of abnormality is the proliferation of autophagic bodies in the inner segments (24), suggesting a role for autophagic cell death in retinal cell degeneration. Mutation of the OPA1 gene causes optic atrophy, in which loss of adult RGCs is accompanied by an increase in the number of autophagosomes in the RGC layer (25). Also, Kim et al. (26) reported that RGC death following optic nerve transection is accompanied by upregulation of autophagy-related genes, such as beclin1 and several Atg genes, and that treatment of the cell line RGC5 with inhibitors of autophagy under serum-deprived

Correspondence: C. Sternberg, Divisão de Pesquisa Clínica, Instituto Nacional de Câncer (INCA) - CPQ, Rua Andre Cavalcanti, 37, 5o andar, 20231-050 Rio de Janeiro, RJ, Brasil. Fax: +55-21-3233-1411. E-mail: csternberg@inca.gov.br

The permanent address of C. Sternberg is Divisão de Pesquisa Clínica, Instituto Nacional de Câncer, Rio de Janeiro, RJ, Brasil

Received June 9, 2010. Accepted August 11, 2010. Available online August 27, 2010. Published October 18, 2010. 
conditions decreases cell viability by approximately $40 \%$ (26). Still, although the role of autophagy in adult RGCs is under scrutiny, there are no available data on the incidence of autophagy in RGCs in the neonatal retina during normal development or following axon damage.

Understanding the molecular pathways by which axonal injury induces neuronal death is important for the development of preventive strategies for rescuing these cells after pathological insults, and also to prevent secondary degeneration among other cell types within the retinal tissue (27). Thus, in the present study, we identified the mode of cell death induced by axotomy of immature RGCs using a model of retinal explants from neonatal rats.

\section{Material and Methods}

\section{Material}

Ac-Leu-Glu-His-Asp-H (aldehyde) (Ac-LEHD-CHO) and Ac-Val-Glu-lle-Asp-H (aldehyde) (Ac-VEID-CHO) were obtained from the Peptide Institute (Japan) and were used at $100 \mu \mathrm{M}$ from a stock solution in DMSO. Ac-Asp-GluVal-Asp-fluoro-methyl-ketone (Z-DEVD-fmk) (Calbiochem, USA) was used at $100 \mu \mathrm{M}$ from a stock solution in DMSO. 3-Methyl-adenine (Sigma, USA) was used at $3 \mu \mathrm{M}$ from a stock solution in culture medium. Ac-VEID-pNa ( $p$-nitroanilide) and Z-DEVD-pNa (Calbiochem) were used at 200 $\mu \mathrm{M}$ from a stock solution in DMSO.

\section{Tissue culture}

Lister hooded rats were used. Retinal explants were prepared as previously described (28). PD1 animals were killed instantaneously according to the policy of the National Institute of Health Guide for the Care and Use of Laboratory Animals, their eyes were removed and the retinas were dissected. Fragments of approximately $1 \mathrm{~mm}^{2}$ were cut in culture medium and placed in 25-mL tight-lidded Erlenmeyer flasks with $5 \mathrm{~mL}$ Eagle's basal medium (Gibco BRL, USA) with $5 \%$ fetal calf serum (WL Immunochemicals, USA) and $20 \mathrm{mM}$ HEPES. The flasks were kept in an orbital shaker at $80-90 \mathrm{revs} / \mathrm{min}$ and at $37^{\circ} \mathrm{C}$ for $24 \mathrm{~h}$. Drugs were added at the beginning of the incubation period.

\section{Histology}

The retinal explants were fixed in $4 \%$ paraformaldehyde in $0.1 \mathrm{M}$ sodium phosphate buffer, $\mathrm{pH} 7.2$, for $1 \mathrm{~h}$ and then infiltrated in a solution of $30 \%$ sucrose in $0.1 \mathrm{M}$ sodium phosphate buffer, pH 7.2. The explants were embedded in optimal cutting temperature medium and $10-\mu \mathrm{m}$ thick transverse sections were cut with a cryostat. The sections were either stained with neutral red or processed for immunohistochemistry.

\section{Immunohistochemistry}

Immunohistochemistry for activated caspase-3 was performed using the CM1 polyclonal antiserum that rec- ognizes activated caspase- 3 without significant crossreactivity with the 32-kDa zymogen form (CM1 was a kind gift from Dr. Anu Srinivasan, Idun Pharmaceuticals, USA). Paraformaldehyde-fixed tissue sections were processed for immunohistochemistry as described previously (29).

\section{Transmission electron microscopy}

Tissue for transmission electron microscopy analysis was processed as described previously (29). Thin sections were collected on copper grids, stained with uranyl acetate and lead citrate, and examined with a JEOL 1210 transmission electron microscope.

\section{Caspase activity assay}

Protein samples were prepared as previously described (29) and Z-DEVD-pNa or VEID-pNA hydrolysis was measured by absorbance at $405 \mathrm{~nm}$ in a 3550-UV Microplate Reader (Bio-Rad, USA).

\section{Quantification of cell death and statistics}

To estimate cell death rates, homogeneously neutral red-stained condensed profiles were counted within the RGC layer from each of three distinct explants in each experiment (minimum of 100 cells/explant). Data are reported as means $\pm S D$ of the replicates from several pooled experiments. The values were normalized with respect to the average rate of cell death within the ganglion cell layer (GCL) in each experiment, which was taken as $100 \%$. Data were analyzed statistically by one- or two-way analysis of variance, using the SPSSPC statistical software.

\section{Results}

\section{Ultrastructural features of axon-damaged neonatal RGCs}

To identify the mode of cell death induced by axotomy in neonatal RGCs, we first examined retinal explants by transmission electron microscopy. Apoptotic hallmarks were observed in dying cells throughout the RGC layer, such as pyknotic nuclei and preserved organelles (Figure $1 \mathrm{~A}, \mathrm{~B})$. Morphologic features of autophagy were also clearly observed in RGCs, such as isolation membranes, i.e., the formation of double-membrane cisterns in the cytoplasm and autophagosomes (Figure 1B,C). The double-membrane cisterns surrounded cytoplasmic contents or whole organelles to form autophagosomes, such as the engulfed mitochondria seen in Figure $1 \mathrm{C}$. Partially degraded cargo within autophagosomes was also observed (Figure 1A, arrows). The morphological pattern of dying RGCs suggested that components of both the apoptotic and autophagic cell death pathways were involved in neonatal RGCs axotomy-induced degeneration. 


\section{Mitochondria are involved in cell death induced by axotomy}

Activation of caspase- 9 depends on the assembly of the mitochondrial apoptosome, a macromolecular complex formed by procaspase- 9 , apoptotic protease activating factor 1, dATP, and cytochrome $c$. Release of cytochrome $c$ is often associated with the opening of a mitochondrial permeability transition pore (mPTP). By using bongkrekic acid, an MPTP inhibitor, we partially blocked cell death induced by axotomy (Figure 2A), showing that cell death induced by RGC deafferentation depends on mitochondrial commitment.

\section{Axotomy induces caspase activation in neonatal RGCs}

To test if the apoptotic features observed at the ultrastructural level were a result of caspase activation, we cultured retinal explants in the presence of peptide inhibi- tors of caspase- $9,-3$ or -6 . LEHD, an inhibitor of caspase-9, partially blocked cell death induced by axotomy (Figure 2B), reaching a maximum effect of nearly $40 \%$ inhibition of cell death. This is consistent with the immunoreactivity for activated caspase- 9 found in the degenerating profiles in the GCL (Figure 2C). DEVD, an inhibitor of caspase-3, partially blocked cell death induced by axotomy (Figure 2D), also in agreement with immunohistochemical data for activated caspase-3 in the GCL (Figure 2E). VEID, an inhibitor of caspase-6, also partially blocked cell death induced by axotomy (Figure 2F). The involvement of caspase-3 and caspase- 6 in RGC degeneration was further confirmed by the demonstration of its activity (Table 1 ).

Taken together, these results indicate that axotomy of neonatal RGCs induces activation of caspase-9, -3 and -6. Partial blockade of cell death by caspase inhibitors, immunohistochemistry and caspase activity data suggest the existence of alternative mechanisms of cell death induced
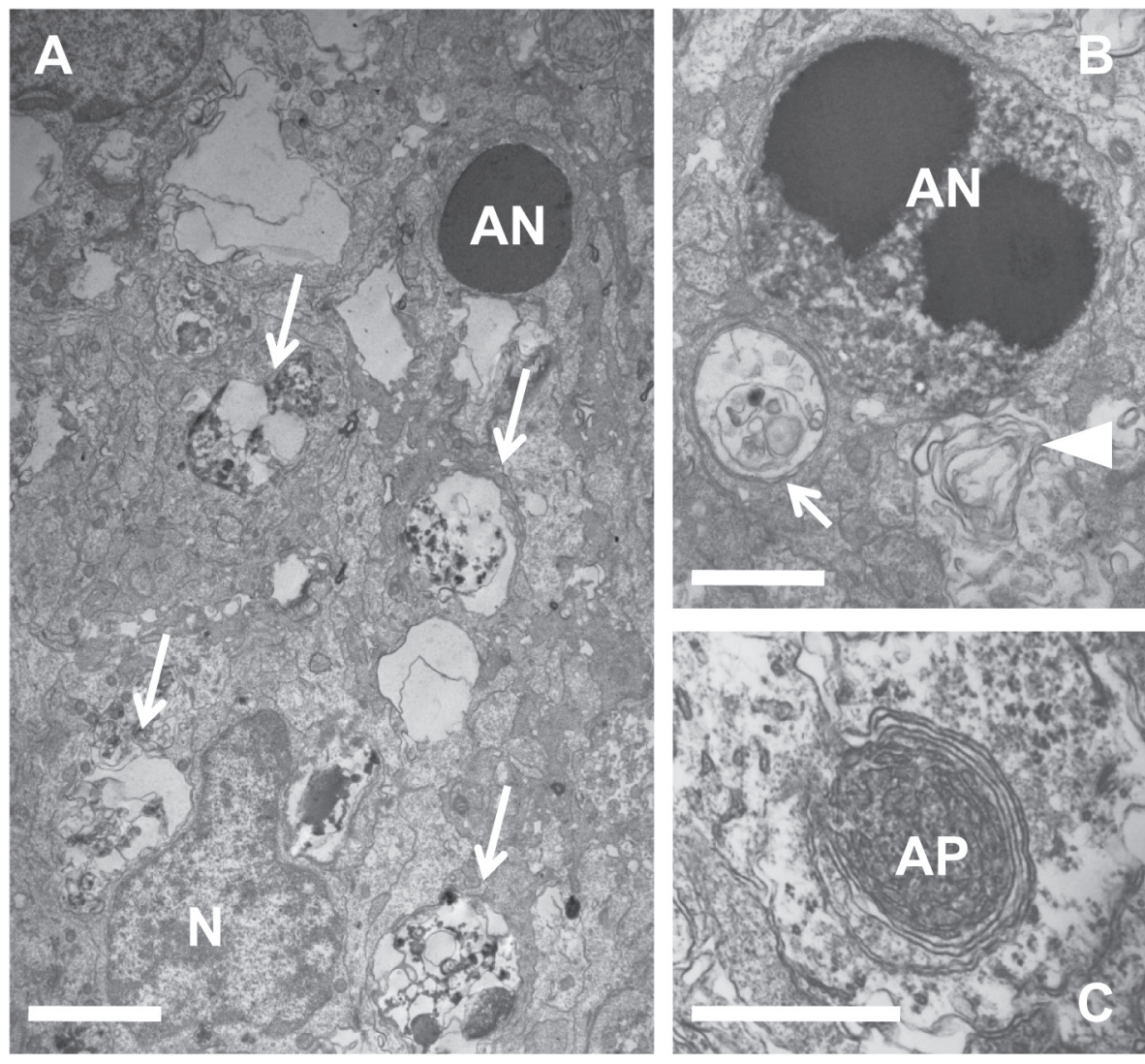

Figure 1. Electron micrographs of autophagy-related vesicular compartments $24 \mathrm{~h}$ after retinal ganglion cells axotomy. Retinal explant sections were obtained from axotomized retinae maintained in vitro for $24 \mathrm{~h}$. Several types of autophagic vacuoles are shown: $A$, Autophagosome-filled profiles (arrows). Scale bar $=5 \mu \mathrm{m}$. B. Double-membraned cisterns (arrowhead) or autophagosome (arrows). Scale bar $=2.5 \mu \mathrm{m}$. $C$, An autophagosome containing recognizable mitochondria (AP). Scale bar $=2.5 \mu \mathrm{m} . \mathrm{N}=$ normal nucleus; $\mathrm{AN}=$ apoptotic nucleus. 
A
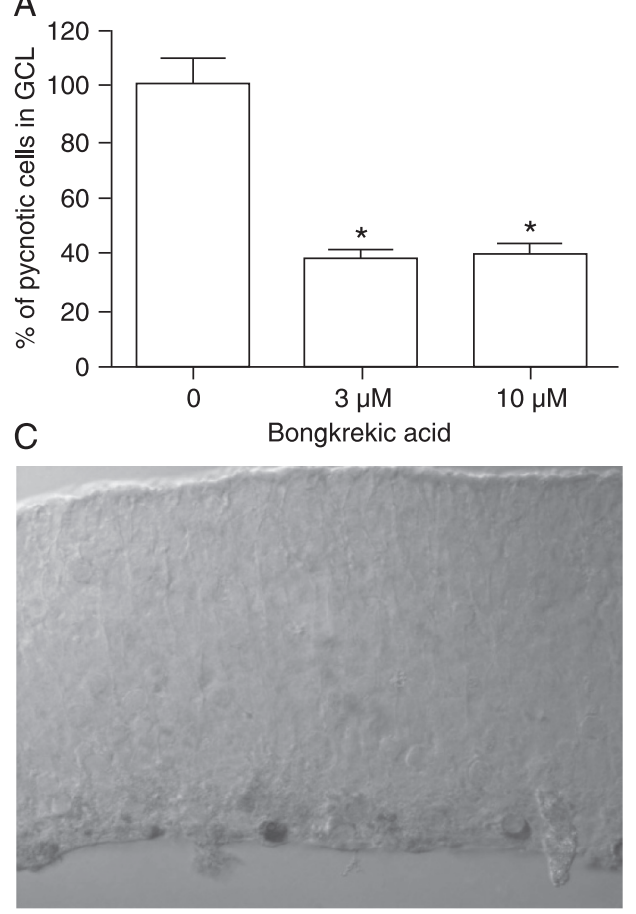

$\mathrm{E}$

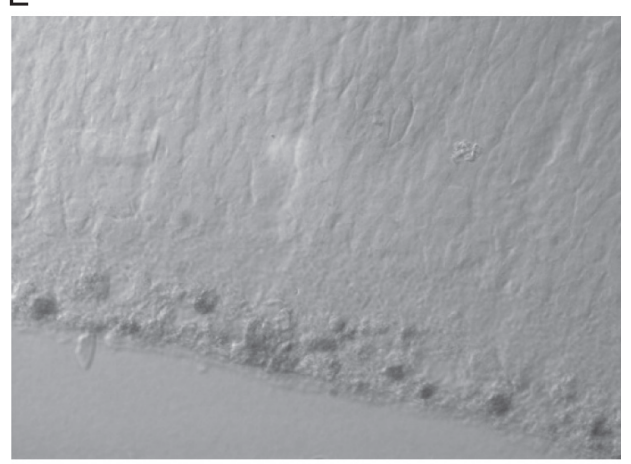

B

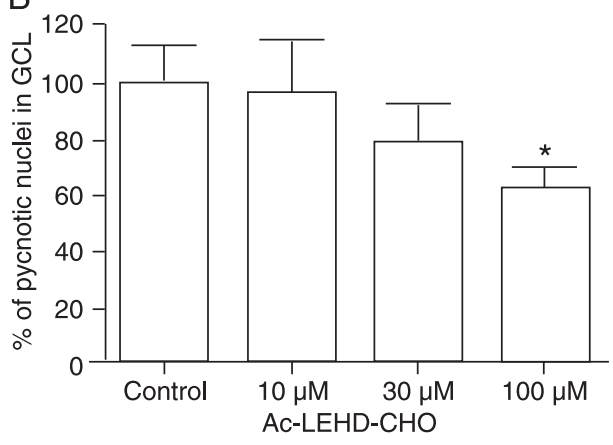

D

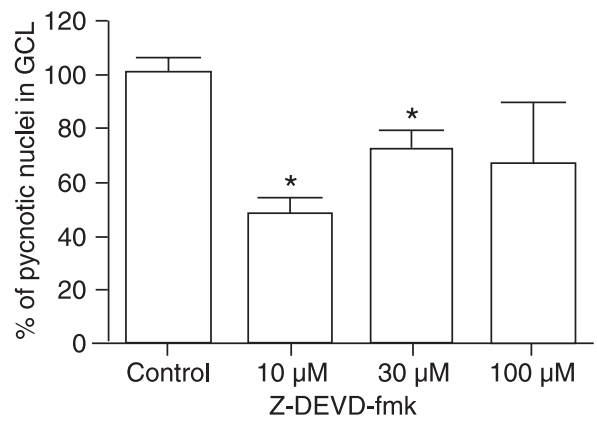

$\mathrm{F}$

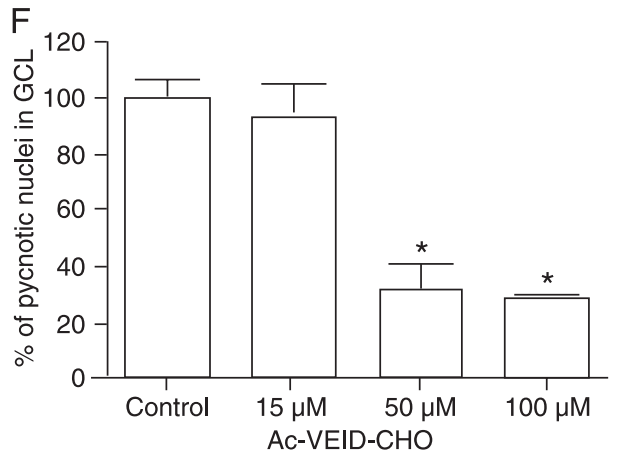

Figure 2. Induction of apoptosis in neonatal retinal ganglion cells. The graph shows the effect of increasing concentrations of: $A$, Bongkrekic acid; $B$, caspase- 9 inhibitor; $D$, caspase- 3 inhibitor, and $F$, caspase- 6 inhibitor on cell death in the ganglion cell layer (GCL) of retinal explants. Cell death was estimated from the density of pyknotic profiles after staining with neutral red. Data were pooled from three independent experiments ( $N=3-9$ for each data), and are reported as mean percent \pm SD density of dead cells in the control preparation (100\%). ${ }^{*} P<0.05$ vs respective control (Mann-Whitney test). $C$, Immunostaining for activated caspase-3; $E$, immunostaining for activated caspase-9.

by optic nerve transection in RGCs.

\section{Induction of autophagy is an anti-apoptotic event in neonatal RGCs}

The ultrastructural analysis unveiled autophagic profiles within the GCL. To test the role of autophagy in the RGCs activated by axon damage, we cultured retinal explants in the presence of 3-methyladenine (3MA), an inhibitor of autophagy (Figure 3). 3MA increased the rate of cell death in GCL (Figure 3). This effect of 3MA is consistent with the view that autophagy has a protective role in immature RGCs in this experimental paradigm.
Table 1. Caspase activation induced by axotomy in neonatal retinal ganglion cells.

\begin{tabular}{lc}
\hline & Enzyme activity $(\mathrm{nmol} / \mathrm{min})$ \\
\hline Caspase-3 & $26.74 \pm 9.25$ \\
Caspase-6 & $6.28 \pm 1.06$ \\
Control & $3.13 \pm 0.36$ \\
\hline
\end{tabular}

Caspase activity is reported as means $\pm \mathrm{SD}$ in $\mathrm{nmol} / \mathrm{min}$. Cleavage of the caspase-3 substrate DEVD-p-nitroanilide or caspase- 6 substrate VEID-p-nitroanilide pooled from two independent experiments $(\mathrm{N}=2-4$ for each data). 


\section{Discussion}

The major findings of the present study were: 1) axotomy induces ultrastructural signs of both apoptosis and autophagy in neonatal RGCs, 2) neonatal RGC death induced by axotomy partially depends on activation of caspase- $9,-3$ and -6 , and 3 ) inhibition of autophagy potentiated the cell death induced in the GCL by axon damage.

Involvement of caspases in neonatal RGC degeneration

Caspase activation in adult RGC death has been extensively documented. Caspase-2, $-3,-8$, and -9 were shown to be involved in in vivo degeneration of RGCs caused by optic nerve section in adult rats $(8,9)$, transient global retinal ischemia degeneration of RGCs and amacrine cells (11) and chronic ocular hypertension-induced cell death, which may contribute to the pathology of glaucoma (10).

Our results demonstrate the activation of at least one initiator and two executor caspases following the axotomy of neonatal RGCs. Activation of caspase-3 in RGC death induced by axotomy was demonstrated in a similar explant model of retinas kept in vitro for 10 days (4), but our results implicate not only caspase-3, but also caspase- 6 and -9 in cell death induced by axotomy of neonatal RGCs. Taken together, these results contribute to the mapping of the mechanisms of the execution of cell death in the developing retina.

\section{Autophagy and neonatal RGC death induced by axon damage}

The ultrastructural analysis of axotomized ganglion cells demonstrated the presence of autophagic profiles within the GCL. Although morphological signs of autophagy are observed in physiological processes in the nervous system (30), several studies implicate autophagy as an important mechanism of programmed cell death both in retina $(28,29,31)$ and other structures of the nervous system (31-35).

Inhibition of autophagy in RGCs potentiated the damaging effect of axotomy, suggesting that autophagy is a tissue response to an insult and a mechanism to delay or block cell degeneration. In fact, such an event was already observed in colon cancer cells, in which mutants with a low rate of autophagy were more sensitive to apoptosis than parental cells, suggesting that autophagy may delay apoptosis by sequestering mitochondrial death-promoting factors such as cytochrome $c$ (36). Our data also agree with studies of the adult retina, in which autophagy-related genes were up-regulated upon induction of cell death by optic nerve transection, and the use of inhibitors of autophagy potentiated cell death induced by serum deprivation in a retinal cell line (26). Thus, autophagy may represent a reaction of the RGCs towards recovery from axon damage, rather than a necessary mechanism of execution of cell death.

Similar to apoptosis, autophagy is also thought to be mediated by the opening of the MPTP (37). Since the opening of the MPTP can cause the release of harmful proteins,

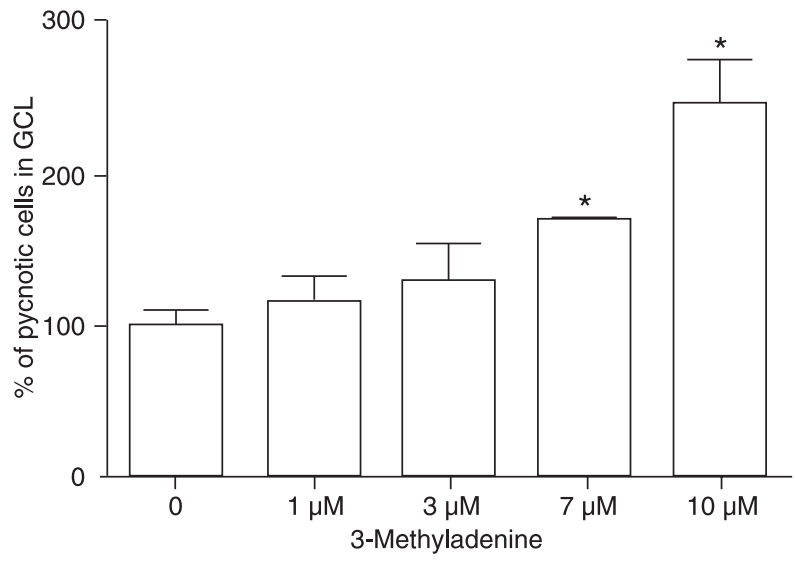

Figure 3. Induction of autophagy in neonatal retinal ganglion cells. The graph shows the effect of increasing concentrations of 3-methyladenine on cell death in the ganglion cell layer (GCL) of retinal explants. Cell death was estimated from the density of pyknotic profiles following staining with neutral red. Data were pooled from two independent experiments $(\mathrm{N}=3-6$ for each data), and are reported as mean percent \pm SD density of dead cells in the control preparation $(100 \%) .{ }^{*} \mathrm{P}<0.05$ vs control (Mann-Whitney test).

the authors suggested that autophagy is a protective device used by cells to rid themselves of damaged mitochondria. Mitochondrial disappearance is also noticed in pathological conditions (38). However, the exact role of mitochondrial disappearance in such conditions is debatable and remains to be elucidated (39).

Our data suggest that axotomy of neonatal RGCs triggers the intrinsic apoptotic pathway. However, it appears that retrograde stress also induces a pro-survival autophagic response, corroborating the growing body of evidence that autophagy can either synergize or counteract the apoptotic pathway. We have shown previously that autophagy constitutes an early stage of the apoptotic process induced by protein synthesis inhibition (29) and its inhibition partially blocks cell degeneration. Both the present and the previous study were conducted on retinal explants at the same postnatal age, but in each case cell death was induced by distinct insults on distinct cell layers, which contain cells at differing stages of differentiation. Taken together, the data from both studies imply that the interaction of apoptosis and autophagy depends on the nature of the insult, the cell type and the stage of differentiation. These observations underscore the need to identify specific pathways and the critical components of cell death programs, since autophagy-inducing drugs are readily available and undergoing clinical trials.

\section{Acknowledgments}

We thank J. Nilson dos Santos (Instituto de Biofísica, Universidade Federal do Rio de Janeiro, Rio de Janeiro, RJ, Brazil) for technical assistance. 


\section{References}

1. Berkelaar M, Clarke DB, Wang YC, Bray GM, Aguayo AJ. Axotomy results in delayed death and apoptosis of retinal ganglion cells in adult rats. J Neurosci 1994; 14: 43684374.

2. Garcia-Valenzuela E, Gorczyca W, Darzynkiewicz Z, Sharma SC. Apoptosis in adult retinal ganglion cells after axotomy. J Neurobiol 1994; 25: 431-438.

3. Levin LA, Louhab A. Apoptosis of retinal ganglion cells in anterior ischemic optic neuropathy. Arch Ophthalmol 1996; 114: 488-491.

4. Manabe S, Kashii S, Honda $\mathrm{Y}$, Yamamoto R, Katsuki H, Akaike A. Quantification of axotomized ganglion cell death by explant culture of the rat retina. Neurosci Lett 2002; 334: 33-36.

5. Aguayo AJ, Clarke DB, Jelsma TN, Kittlerova P, Friedman $\mathrm{HC}$, Bray GM. Effects of neurotrophins on the survival and regrowth of injured retinal neurons. Ciba Found Symp 1996; 196: 135-144.

6. Peinado-Ramon P, Salvador M, Villegas-Perez MP, VidalSanz M. Effects of axotomy and intraocular administration of NT-4, NT-3, and brain-derived neurotrophic factor on the survival of adult rat retinal ganglion cells. A quantitative in vivo study. Invest Ophthalmol Vis Sci 1996; 37: 489-500.

7. Rajan P, Stewart CL, Fink JS. LIF-mediated activation of STAT proteins after neuronal injury in vivo. Neuroreport 1995; 6: 2240-2244.

8. Chaudhary P, Ahmed F, Quebada P, Sharma SC. Caspase inhibitors block the retinal ganglion cell death following optic nerve transection. Brain Res Mol Brain Res 1999; 67: 3645.

9. Kermer P, Ankerhold R, Klocker N, Krajewski S, Reed JC, Bahr M. Caspase-9: involvement in secondary death of axotomized rat retinal ganglion cells in vivo. Brain Res Mol Brain Res 2000; 85: 144-150.

10. McKinnon SJ, Lehman DM, Kerrigan-Baumrind LA, Merges CA, Pease ME, Kerrigan DF, et al. Caspase activation and amyloid precursor protein cleavage in rat ocular hypertension. Invest Ophthalmol Vis Sci 2002; 43: 1077-1087.

11. Singh M, Savitz SI, Hoque R, Gupta G, Roth S, Rosenbaum PS, et al. Cell-specific caspase expression by different neuronal phenotypes in transient retinal ischemia. $J$ Neurochem 2001; 77: 466-475.

12. Yoshizawa K, Nambu H, Yang J, Oishi Y, Senzaki H, Shikata $\mathrm{N}$, et al. Mechanisms of photoreceptor cell apoptosis induced by N-methyl-N-nitrosourea in Sprague-Dawley rats. Lab Invest 1999; 79: 1359-1367.

13. Hisatomi T, Sakamoto T, Murata T, Yamanaka I, Oshima $Y$, Hata Y, et al. Relocalization of apoptosis-inducing factor in photoreceptor apoptosis induced by retinal detachment in vivo. Am J Pathol 2001; 158: 1271-1278.

14. Rehen SK, Ary-Pires R, Linden R. Intraretinal neurotrophic activity prevents the degeneration of ganglion cells in retinal explants. Braz J Med Biol Res 1993; 26: 955-959.

15. Rabacchi SA, Bonfanti L, Liu XH, Maffei L. Apoptotic cell death induced by optic nerve lesion in the neonatal rat. $J$ Neurosci 1994; 14: 5292-5301.

16. Rehen SK, Neves DD, Fragel-Madeira L, Britto LR, Linden $R$. Selective sensitivity of early postmitotic retinal cells to apoptosis induced by inhibition of protein synthesis. Eur $J$
Neurosci 1999; 11: 4349-4356.

17. Ary-Pires R, Nakatani M, Rehen SK, Linden R. Developmentally regulated release of intraretinal neurotrophic factors in vitro. Int J Dev Neurosci 1997; 15: 239-255.

18. Geiger LK, Kortuem KR, Alexejun C, Levin LA. Reduced redox state allows prolonged survival of axotomized neonatal retinal ganglion cells. Neuroscience 2002; 109: 635-642.

19. Bonfanti L, Strettoi E, Chierzi S, Cenni MC, Liu XH, Martinou $\mathrm{J}-\mathrm{C}$, et al. Protection of retinal ganglion cells from natural and axotomy-induced cell death in neonatal transgenic mice overexpressing bcl-2. J Neurosci 1996; 16: 4186-4194.

20. McKernan DP, Caplis C, Donovan M, O'Brien CJ, Cotter TG. Age-dependent susceptibility of the retinal ganglion cell layer to cell death. Invest Ophthalmol Vis Sci 2006; 47: 807-814.

21. Spalding KL, Dharmarajan AM, Harvey AR. Caspaseindependent retinal ganglion cell death after target ablation in the neonatal rat. Eur J Neurosci 2005; 21: 33-45.

22. Assuncao GC, Linden R. Programmed cell deaths. Apoptosis and alternative deathstyles. Eur J Biochem 2004; 271: 1638-1650.

23. Tait SW, Green DR. Caspase-independent cell death: leaving the set without the final cut. Oncogene 2008; 27: 64526461.

24. Moriya M, Baker BN, Williams TP. Progression and reversibility of early light-induced alterations in rat retinal rods. Cell Tissue Res 1986; 246: 607-621.

25. White KE, Davies VJ, Hogan VE, Piechota MJ, Nichols PP, Turnbull DM, et al. OPA1 deficiency associated with increased autophagy in retinal ganglion cells in a murine model of dominant optic atrophy. Invest Ophthalmol Vis Sci 2009; 50: 2567-2571.

26. Kim SH, Munemasa Y, Kwong JM, Ahn JH, Mareninov S, Gordon LK, et al. Activation of autophagy in retinal ganglion cells. J Neurosci Res 2008; 86: 2943-2951.

27. Cusato K, Stagg SB, Reese BE. Two phases of increased cell death in the inner retina following early elimination of the ganglion cell population. J Comp Neurol 2001; 439: 440449.

28. de Araujo EG, Linden R. Trophic factors produced by retinal cells increase the survival of retinal ganglion cells in vitro. Eur J Neurosci 1993; 5: 1181-1188.

29. Guimaraes CA, Benchimol M, Amarante-Mendes GP, Linden R. Alternative programs of cell death in developing retinal tissue. J Biol Chem 2003; 278: 41938-41946.

30. Petersen A, Larsen KE, Behr GG, Romero N, Przedborski $S$, Brundin $P$, et al. Expanded CAG repeats in exon 1 of the Huntington's disease gene stimulate dopamine-mediated striatal neuron autophagy and degeneration. Hum $\mathrm{Mol}$ Genet 2001; 10: 1243-1254.

31. Reme CE, Wolfrum U, Imsand C, Hafezi F, Williams TP. Photoreceptor autophagy: effects of light history on number and opsin content of degradative vacuoles. Invest Ophthalmol Vis Sci 1999; 40: 2398-2404.

32. Boellaard JW, Kao M, Schlote W, Diringer H. Neuronal autophagy in experimental scrapie. Acta Neuropathol 1991; 82: $225-228$.

33. Cataldo AM, Hamilton DJ, Barnett JL, Paskevich PA, Nixon RA. Properties of the endosomal-lysosomal system in the human central nervous system: disturbances mark most 
neurons in populations at risk to degenerate in Alzheimer's disease. J Neurosci 1996; 16: 186-199.

34. Anglade P, Vyas S, Javoy-Agid F, Herrero MT, Michel PP, Marquez J, et al. Apoptosis and autophagy in nigral neurons of patients with Parkinson's disease. Histol Histopathol 1997; 12: 25-31.

35. Stefanis L, Larsen KE, Rideout HJ, Sulzer D, Greene LA. Expression of A53T mutant but not wild-type alpha-synuclein in PC12 cells induces alterations of the ubiquitin-dependent degradation system, loss of dopamine release, and autophagic cell death. J Neurosci 2001; 21: 9549-9560.

36. Bauvy C, Gane P, Arico S, Codogno P, Ogier-Denis E. Autophagy delays sulindac sulfide-induced apoptosis in the human intestinal colon cancer cell line HT-29. Exp Cell Res
2001; 268: 139-149.

37. Lemasters JJ, Nieminen AL, Qian T, Trost LC, Elmore SP, Nishimura $Y$, et al. The mitochondrial permeability transition in cell death: a common mechanism in necrosis, apoptosis and autophagy. Biochim Biophys Acta 1998; 1366: 177196.

38. Xue L, Fletcher GC, Tolkovsky AM. Mitochondria are selectively eliminated from eukaryotic cells after blockade of caspases during apoptosis. Curr Biol 2001; 11: 361-365.

39. Tolkovsky AM, Xue L, Fletcher GC, Borutaite V. Mitochondrial disappearance from cells: a clue to the role of autophagy in programmed cell death and disease? Biochimie 2002; 84: 233-240. 